\title{
Analysis of fluid lubrication mechanisms in metal forming at mesoscopic scale
}

Dubar, L.; Hubert, C.; Christiansen, Peter; Bay, Niels; Dubois, A.

Published in:

C I R P Annals

Link to article, DOI:

10.1016/j.cirp.2012.03.126

Publication date:

2012

Link back to DTU Orbit

Citation (APA):

Dubar, L., Hubert, C., Christiansen, P., Bay, N., \& Dubois, A. (2012). Analysis of fluid lubrication mechanisms in metal forming at mesoscopic scale. C I R P Annals, 61(1), 271-274. https://doi.org/10.1016/j.cirp.2012.03.126

\section{General rights}

Copyright and moral rights for the publications made accessible in the public portal are retained by the authors and/or other copyright owners and it is a condition of accessing publications that users recognise and abide by the legal requirements associated with these rights.

- Users may download and print one copy of any publication from the public portal for the purpose of private study or research.

- You may not further distribute the material or use it for any profit-making activity or commercial gain

- You may freely distribute the URL identifying the publication in the public portal

If you believe that this document breaches copyright please contact us providing details, and we will remove access to the work immediately and investigate your claim. 


\title{
Analysis of fluid lubrication mechanisms in metal forming at mesoscopic scale
}

\author{
L. Dubar ${ }^{1}$, C. Hubert ${ }^{1}$, P. Christiansen ${ }^{2}$, N. Bay ${ }^{2}$ (1), A. Dubois ${ }^{1}$ \\ ${ }^{1}$ University of Valenciennes and Hainaut Cambresis, TEMPO EA 4542, France \\ ${ }^{2}$ Department of Mechanical Engineering, Technical University of Denmark, Denmark
}

\begin{abstract}
The lubricant entrapment and escape phenomena in metal forming are studied experimentally as well as numerically. Experiments are carried out in strip reduction of aluminium sheet applying a transparent die to study the fluid flow between mesoscopic cavities. The numerical analysis involves two computation steps. The first one is a fully coupled fluid-structure Finite Element computation, where pockets in the surface are plastically deformed leading to the pressurization of the entrapped fluid. The second step computes the fluid exchange between cavities through the plateaus of asperity contacts with the plane tool, one cavity at a time.
\end{abstract}

Metal forming, fluid lubrication mechanisms, analysis on mesoscopic scale

\section{Introduction}

Many metal forming operations involve liquid lubricants to reduce friction at the tool/part interface and to improve the finished part surface quality. In most of these operations the mixed lubrication regime appears, leading to local asperity contact between the tool and part surfaces in between pockets functioning as micro-reservoirs for the lubricant. During processing the reservoirs are deformed and the entrapped lubricant is pressurized and eventually escaping by Micro Plasto Hydrodynamic Lubrication, leading to local, non-uniform deformation of the surface layer. It is of great importance to understand and control the lubrication phenomena in order to reduce friction and improve the resulting surface quality.

The concept of Micro Plasto Hydrodynamic Lubrication (MPHL) was proposed by Mizuno [1], and later supported by Kudo et al. [2]. Azushima et al. [3] and Bech et al. [4] proved the concept in plane strain reduction of aluminium strips provided with pyramidal indentations filled with lubricant. The lubricant transport was observed through a transparent glass die. Bech et al. [4] established a mathematical model to quantify the hydrodynamic film formation during thickness reduction, leading to realistic and promising results. The hydrostatic pressure in the lubricant pocket was furthermore quantified in their experiments.

The present work involves numerical as well as experimental analysis of the lubrication mechanisms, applying the numerical strategy developed by Deltombe et al. [5] to quantify the final shape of the lubricant pockets, taking into account both the hydrostatic and the hydrodynamic behaviour of the lubricant. The strategy is based on a weak fluid/structure coupling involving the Finite Element Method (FEM) and analytical calculations.

This strategy was adopted in a previous study by the authors [6], where experimental validation in strip reduction was carried out with pyramidal pockets implying a 3D pocket geometry, which for simplicity was modelled in 2D. In order to ensure a more fair comparison of the numerical 2D model and the experimental model oblong, groove shaped pockets perpendicular to the drawing direction are applied in the present investigation with the aim of reducing the effect of lubricant escape from pocket corners pointed out in the earlier study.

\section{Numerical model for fluid exchange calculation}

The numerical methodology developed in [5] involves a fully coupled fluid-structure computation for its initialization, performed on the commercial Finite Element (FE) code ABAQUS/Standard, without lubricant exchange, followed by a computation loop including two calculation steps. The first step is performed by an external subroutine computing the fluid supply to or leakage from the lubricant reservoirs (so-called cavities or pockets in the following) according to the current pressure in the pockets and the relative velocity between die and asperity plateau. The calculated fluid rates are then applied as boundary conditions to a new fluid-structure computation. These two steps, that correspond to one time step, are involved in a loop which is continued until the whole computation time is reached. The next two sections describe the calculation steps in more details.

\subsection{Fully coupled fluid-structure computation}

The FE model involves both dies, modelled as rigid bodies, and the strip provided with cavities, modelled with 2D fluid link elements. The FE model is illustrated in Fig. 1 with its geometrical parameters adjusted to fit the experimental testing conditions mentioned in section 4 .

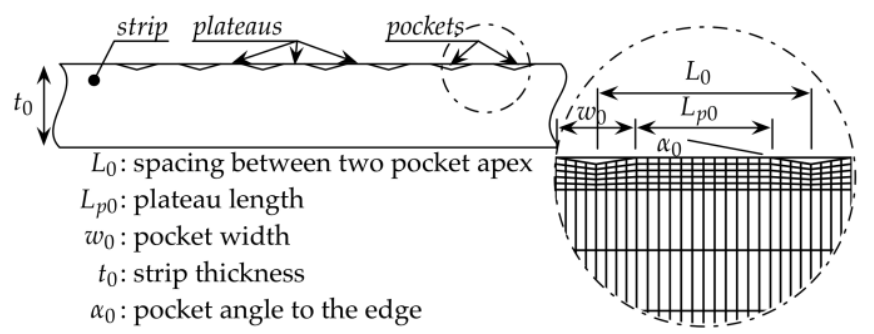

Figure 1. Finite Element model configuration 
During the calculation the fluid interacts with the solid elements, leading to modifications of the fluid pressure owing to the plastic deformation of the strip. By the end of the calculation, the new pressure state is known for all the cavities, as well as the asperity plateau contact length and relative velocity between die and strip asperity plateaus. The second calculation step, detailed in the next section, applies these results to calculate the fluid supply or leakage related to each cavity.

\subsection{Fluid flow computation at the cavity level}

The lubricant flow rates $q_{i j}$ related to the $i^{\text {th }}$ cavity in the FE model are calculated using a development of the local Couette's equation in terms of pressure gradient:

$q_{i 1}=-\frac{h^{3}}{12 \eta} \frac{\Delta p_{i 1}}{\Delta x_{i 1}}+u_{1} h \quad$ and $\quad q_{i 2}=-\frac{h^{3}}{12 \eta} \frac{\Delta p_{i 2}}{\Delta x_{i 2}}-u_{2} h$

where $h$ is the lubricant film thickness between the die and the asperity plateaus, $\eta$ is the lubricant's dynamic viscosity coefficient, $\Delta p_{i j}$ is the pressure gradient between the current cavity and the previous cavity (if $j=1$ ) or the subsequent cavity (if $j=2$ ), $u_{j}$ is the relative tool/plateau velocity and $\Delta x_{i j}$ is the previous or subsequent plateau length, depending on $j$. The parameters detailed above are illustrated in Fig. 2.

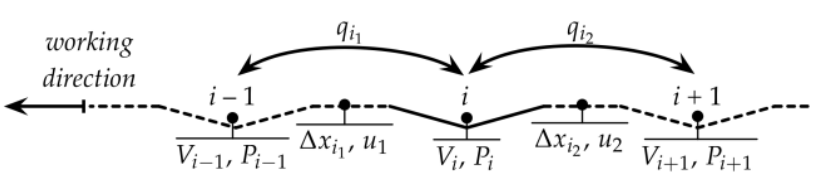

Figure 2. Illustration of fluid exchange between lubricant pockets.

In the flow rate calculations, $\eta$ and $h$ are fixed, and $\Delta p, \Delta x_{i j}$ and $u_{j}$ are obtained from the FE calculation. The flow rates $q_{i j}$ are then summed to obtain the global flow rate $q_{i}=q_{i 1}+q_{i 2}$ related to each cavity, its sign indicating whether flow is into or out of the cavity. Whatever its sign is, the global amount of fluid is preserved taking into account the special cases at the contact entry and exit. In these locations the pressure gradient in the considered cavity is calculated against atmospheric pressure since this cavity is "open", leading to a large fluid volume leakage at these locations, given by $V_{i}^{*}=q_{i} \Delta t$. In any case, the result is a decrease of the lubricant pocket volume resulting in cavities flattening.

\section{Experimental investigations}

\subsection{Testing device and design of experiments}

The experimental testing device used in this study is developed by Bech et al. [4] for thickness reduction of aluminium strips provided with cavities filled with lubricant. Using an upper die of hardened glass direct observation of lubricant entrapment and escape during drawing is enabled, Fig. 3. The thickness reduction is ensured by an inclined lower steel die. The drawing speed $V_{s}$ is adjustable. The hardened glass die is used as delivered in form of a circular disc of dimensions $\emptyset 50 \times 11 \mathrm{~mm}$. The lower die of tool steel is $80 \mathrm{~mm}$ long, $50 \mathrm{~mm}$ wide, with die angle $\beta=3^{\circ}$. It is polished to reduce friction. A high speed video camera is used for subsequent analysis of lubricant escape, including location of onset of escape, direction of escape and front wave speed.

Mesoscopic pockets are manufactured on the upper strip surface to model the influence of micro-pockets appearing in a real surface. Contrarily to previous experiments performed by the authors [6] these pockets are in shape of triangular grooves to ensure plane strain behaviour of the lubricant. Furthermore, the pockets are manufactured by Electro Discharge Machining (EDM) leading to sharp pocket edges without any banks, which appeared to be a problem with the earlier pockets produced by pyramidal indentations.

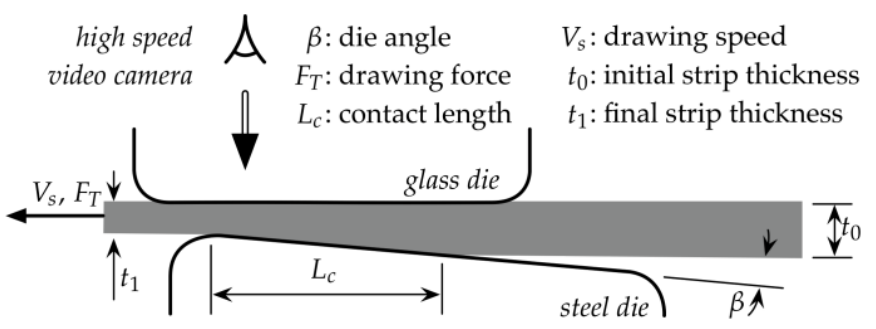

Figure 3. Schema of the experimental testing device.

The strip material is semi-hard aluminium AISI 1050, $\mathrm{H} 24$, with dimensions $l_{0} \times b_{0} \times t_{0}=450 \times 20 \times 2 \mathrm{~mm}$. As shown in Fig. 4 the pockets are $1 \mathrm{~mm}$ wide and $10 \mathrm{~mm}$ long, with a spacing of $2 \mathrm{~mm}$. In the present study the pocket's angle to the edge is $\alpha_{0}=5^{\circ}$.
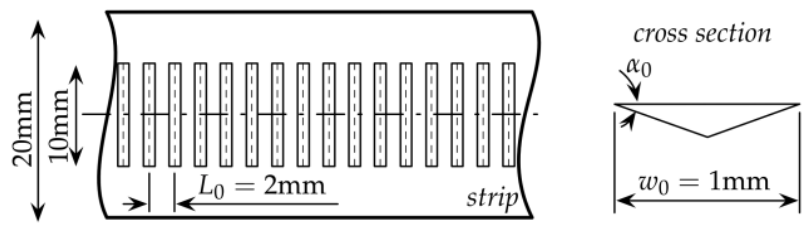

Figure 4. Groove shaped pockets pattern.

Test conditions are outlined in Table 1 indicating two different drawing speeds and two different viscosities of the applied, pure mineral oil. Observation of lubricant flow is done with a high speed video camera with frame rates of $f_{r 1}=125 \mathrm{fps}$ for $V_{s 1}=5 \mathrm{~mm} / \mathrm{s}$ and $f_{r 2}=1500 \mathrm{fps}$ for $V_{s 2}=50 \mathrm{~mm} / \mathrm{s}$.

All four possible combinations of drawing speed and velocity are carried out performing three tests per configuration. During the tests the drawing speed and force are recorded, the latter in order to calibrate friction in the FE model. The test configurations are summed up in Table 1 and their individual abbreviation is given in the last column.

Table 1. Testing conditions (target values) and corresponding test.

\begin{tabular}{cllr} 
Pocket angle & Drawing velocity & Lub. viscosity $\left(40^{\circ} \mathrm{C}\right)$ & Test No. \\
\hline \multirow{3}{*}{$\alpha_{0}=5^{\circ}$} & $V_{s 1}=5 \mathrm{~mm} / \mathrm{s}$ & $\eta_{1}=0.05373$ Pas & 5DTC1 \\
\cline { 2 - 4 } & \multirow{2}{*}{$V_{s 2}=50 \mathrm{~mm} / \mathrm{s}$} & $\eta_{2}=0.5954$ Pas & 5DTC2 \\
\cline { 3 - 4 } & & $\eta_{2}=0.05373$ Pas & 5DTC3 \\
\hline
\end{tabular}

\subsection{Real pocket geometry and final depth}

The dimensions given in Fig. 4 are target values that are difficult to respect, mainly because of electrode wear during the EDM. The actual test parameters are given in Table 2 for each test configuration, together with the measured initial and final pocket depth $d_{0}$ and $d_{1}$.

\subsection{Validation of lubricant exchange assumption}

An important point to verify experimentally is the assumption of fluid exchange between the pockets during 
Table 2. Initial and final strip thickness and surface topography. Parameters defined in Fig. 1.

\begin{tabular}{ccccc} 
Parameter & 5DTC1 & 5DTC2 & 5DTC3 & 5DTC4 \\
\hline$t_{0}(\mathrm{~mm})$ & 1.96 & 1.96 & 1.96 & 1.96 \\
\hline$t_{1}(\mathrm{~mm})$ & 1.68 & 1.68 & 1.59 & 1.68 \\
\hline $\mathrm{W}_{0}(\mathrm{~mm})$ & 1.34 & 1.36 & 1.44 & 0.97 \\
\hline$L_{p 0}(\mathrm{~mm})$ & 0.66 & 0.64 & 0.56 & 1.03 \\
\hline$\alpha_{0}$ & $3.69^{\circ}$ & $4.99^{\circ}$ & $4.68^{\circ}$ & $3.73^{\circ}$ \\
\hline$d_{0}(\mu \mathrm{m})$ & 39 & 51 & 54 & 25 \\
\hline$d_{1}(\mu \mathrm{m})$ & 5 & 9 & 17 & 7
\end{tabular}

drawing. Fig. 5 shows two pictures of different lubricant escape from a given cavity during drawing, i.e. backward in Fig. 5a and forward in Fig. 5b. The drawing direction is downward; the front of one of the lubricant waves has been highlighted with a dashed line for easier identification, and the escape direction and range is given by the arrows.

As postulated by Bech et al. [4], backward lubricant escape (Fig. 5a) is mainly governed by the drawing speed and lubricant viscosity, the lubricant being dragged out of the cavity by viscous shear forces. In Fig. 5a, the highlighted lubricant wave front reaches beyond the subsequent pocket entering the bite with a velocity that almost corresponds to the drawing velocity. The case of forward escape (Fig. 5b) is due to the lubricant pressure increase inside a cavity overcoming the sealing pressure. This mechanism is caused by the decrease in contact pressure towards the exit, again according to Bech et al. [4]. The phenomenon is also observed here: once the sealing pressure is reached the lubricant escapes very fast and feeds the preceding pocket, sometimes even the preceding two pockets. The assumption of lubricant exchange between cavities is thus verified visually.

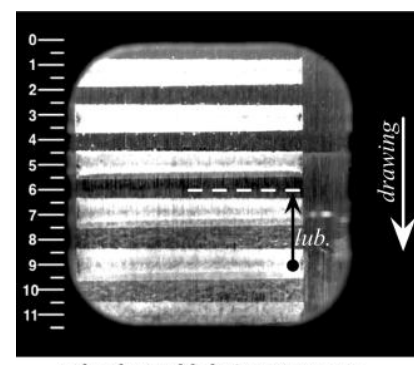

a. backward lubricant escape.

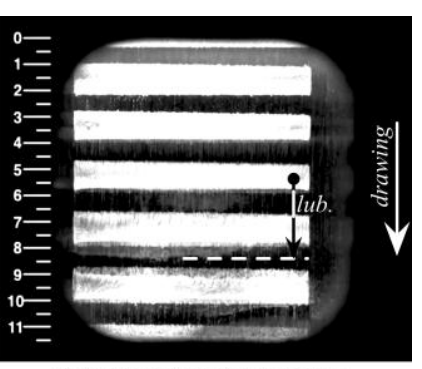

b. forward lubricant escape.
Figure 5. Illustration of lubricant escape during drawing.

The two escape mechanisms are called Micro Plasto HydroDynamic Lubrication (MPHDL) and Micro Plasto HydroStatic Lubrication (MPHSL). They are represented in the implemented Couette's equation (Eqns. 1) by the first and second expression.

\section{Experimental-Numerical comparison}

\subsection{Set-up of Finite Element models}

Firstly, the geometry of the FE models related to each test configuration is adjusted to match the actual, experimental ones, given in Table 2 .

Secondly, friction in the contact between tool and workpiece must be determined. Coulomb's law is adopted and two friction coefficients should ideally be identified, one for each tool surface. The test allows, however, only determination of one value based on measurements of the drawing force and inverse analysis, implying that an average friction coefficient will be assumed for the FE models. The friction coefficient obtained this way ensures correct global force response of the FE model and since it turns out to have no significant influence on the calculated lubricant flow the applied method is considered satisfactory. The friction coefficients determined for the four test configurations range from 0.03 to 0.17 .

\subsection{Determination of the lubricant film thickness}

In the mixed lubrication regime the average roughness $R_{a}$ after forming is normally considered to be a good estimate of the lubricant film thickness [7]. In the present study the same assumption is applied on the plateaus between neighbouring lubricant pockets. Measurements are done after testing using a 3D profilometer on square plateau region of dimension $0.5 \times 0.5 \mathrm{~mm}^{2}$ and the roughness is determined along three lines, perpendicular to the drawing direction. The determined film thicknesses are consistent with earlier ones by Bech et al. [4]. They are given in Table 3 together with their lower and upper bounds, for each testing condition.

Table 3. Determined lubricant film thicknesses.

\begin{tabular}{ccccc} 
Test No. & 5DTC1 & 5DTC2 & 5DTC3 & 5DTC4 \\
\hline Lower bound $(\mu \mathrm{m})$ & 0.417 & 0.060 & 0.221 & 0.234 \\
\hline Mean value $(\mu \mathrm{m})$ & $\mathbf{0 . 5 0 9}$ & $\mathbf{0 . 1 3 2}$ & $\mathbf{0 . 3 0 0}$ & $\mathbf{0 . 7 4 7}$ \\
\hline Upper bound $(\mu \mathrm{m})$ & 0.601 & 0.204 & 0.379 & 1.260
\end{tabular}

The roughness measurement is local and may be strongly modified depending on the lubricant flow as noticed by Bech et al. [4], who observed significant increase in roughness in regions where lubricant escape occurred. This explains the important differences observed when comparing the tests two by two. The video recordings in tests 5DTC2 and 5DTC3 that give the lowest roughness values in Table 3 , showed accidental, much localized lubricant escape from the groove corners instead of the intended uniform flow from the groove edges. As a result the film thickness on the plateaus becomes much less than if the lubricant flow had been homogenously distributed.

The roughness mapping from condition 5DTC3 showed a very smooth surface with an average roughness $R_{a}=0.300 \mu \mathrm{m}$ and a height amplitude of $3 \mu \mathrm{m}$. Compared to this the test 5DTC4 has a height amplitude of $10 \mu \mathrm{m}$, and an average roughness $\mathrm{R}_{\mathrm{a}}=0.747 \mu \mathrm{m}$, while the initial strip surface roughness was $\mathrm{R}_{\mathrm{a} 0}=$ $0.463 \mu \mathrm{m}$. The lubricant escape in test 5DTC3 from the pocket corners instead of the front edge leads to less lubricant on the plateaus implying a mixed or even boundary lubrication regime with an improved surface quality as a result. On the contrary test 5DTC4 with lubricant escape to the plateau results in surface roughening. The same difference is observed when comparing tests 5DTC1 and 5DTC2.

\subsection{Experimental and numerical depth of final pocket}

The 2D FE model leaves the pocket depth as the most relevant characteristic when validating the model by comparisons with experiments. The numerical model allows monitoring of the pocket evolution when passing through the deformation zone, and comparison with the experiments is achieved in terms of final depth. For each test condition (Table 2), the computation is given for the mean value as well as for the lower and upper bound of the film thickness shown in Table 3, indicating the large scatter of this parameter and the difficulties to determine a representative value.

Fig. 6 shows the results for test 5DTC1. The read curve represents the cavity depth development predicted on basis of the mean film thickness, whereas the read shaded area shows the variation in predicted cavity depth within the film thickness range listed in Table 3. A strong decrease in pocket depth is 
noticed at the entrance before the cavity is fully covered by the glass die. It corresponds to a significant lubricant escape caused by the pressure gradient related to the considered cavity towards the neighbouring inlet zone with atmospheric pressure. Once the cavity is fully closed, the cavity depth evolution is much less pronounced but varying in a non-monotonic way owing to other cavities entering and exiting the contact zone. At the end of the contact, the pressure gradient of the pocket is again computed against atmospheric pressure, leading to fluid loss from the cavity to the exit implying a cavity depth reduction.

Fig. 6 shows that the mean allows good prediction of the final cavity depth, but the depth prediction is very sensitive to the lubricant film thickness adopted. The figure shows a final depth corridor range of $0 \leq d_{1} \leq 23 \mu \mathrm{m}$.

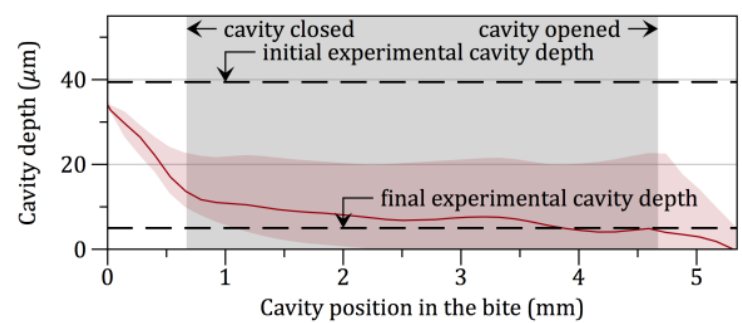

Figure 6. Numerical and experimental cavities depth for cond. 5DTC1.

In test 5DTC4 the same observation is made as in 5DTC1 concerning the sensitivity of the lubricant film thickness, which is explained by the wide film thickness range observed in this case, see Table 3. With this range the calculated final cavity depth lies in the range $5 \leq d_{1} \leq 24 \mu \mathrm{m}$, while the final experimental cavity depth is $d_{1}=7 \mu \mathrm{m}$. The one predicted for the mean film thickness is $d_{1}=20 \mu \mathrm{m}$.

The results highlight the importance of determining the film thickness accurately. This is emphasized by the fact that $h$ is raised to the power of 3 in the Couette equation (1) implying decisive influence on the lubricant flow rate.

The predicted cavity depths for conditions 5DTC2 and 5DTC3 are completely different from 5DTC1 and 5DTC4. As explained in Section 4.2 escape of lubricant in these two tests was very inhomogeneous mainly occurring from the groove corners resulting in small film thickness on the plateaus.

Since the model does not take this alternative lubricant flow into account it fails to predict the experimentally observed cavity depth reduction. This behaviour was less significant in the case of pyramidal indentations (Hubert et al. [6]), where the lubricant flow from the corners was rapidly merged in between the pockets because of their small width $(1 \mathrm{~mm})$. As seen in Fig. 7 the prediction of pocket depth development in case of pyramidal indentations were in good agreement with the experimentally measured. As such it must be concluded that the earlier applied experimental technique with pyramidal indentations is probably a better way to validate the model, which, however, is able to simulate the process when lubricant escape occurs in the modelling plane.

\section{Conclusions}

An experimental and numerical study of lubricant entrapment and escape in/from mesoscopic pockets was carried out in aluminium strip drawing. The aim of the experimental investigation was to obtain reliable data to supply the numerical model, which is based on development of the local Couette's equation and on the hypothesis of lubricant exchange between cavities.

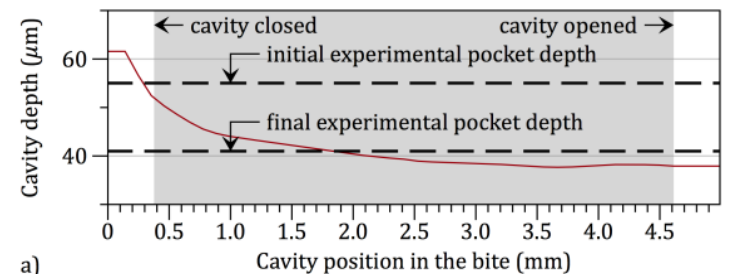

a) Cavity position in the bite $(\mathrm{mm})$

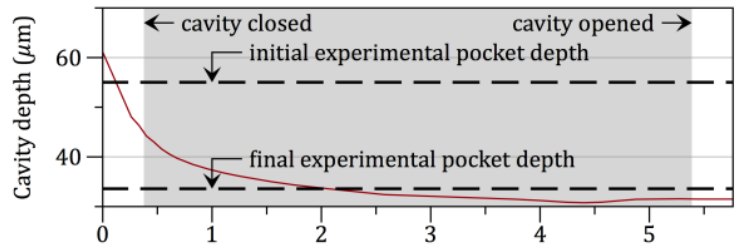

b) Cavity position in the bite $(\mathrm{mm})$

Figure 7. Predicted and measured cavity depths for pyramidal cavities, a) $=0.5 \mathrm{~mm} / \mathrm{s}, \quad \mu \mathrm{m} ; \mathrm{b}) \quad \mathrm{mm} / \mathrm{s}, \quad \mu \mathrm{m}$, Hubert et al. [6].

Visual observations proved the validity of this hypothesis showing lubricant escape from the observed cavities to the neighbouring ones. The model clearly identifies the lubricant film thickness as a key parameter, which is difficult to determine. Further investigations may be carried out to get statistically based film thicknesses rather than deterministic values which among others are heavily influenced by the measurement location.

The model is not able to predict consistent cavities depth reduction for two tests cases, where the visual observations showed lubricant escape to be highly inhomogeneous occurring from the corner points. This is, however, considered to be an experimental rather than a numerical error. Even a true 3D deformation of a 3D surface with for example circular pockets may be possible to model rather realistically with the simple 2D model as long as lubricant flow is homogeneous. The difficulties observed are merely due to very inhomogeneous flow caused by the special pocket geometry.

\section{Acknowledgements}

The present research work has been supported by International Campus on Safety and Intermodality in Transportation the Nord-Pas-de-Calais Region, the European Community, the Regional Delegation for Research and Technology, the Ministry of Higher Education and Research, and the National Centre for Scientific Research. The authors gratefully acknowledge the support of these institutions.

\section{References}

[1] Mizuno, T., Okamoto, M., 1982, Effects of lubricant viscosity at pressure and sliding velocity on lubricating conditions in the compression-friction test on sheet metals, J. Lubr. Technol. 104:53-59.

[2] Kudo, H., Tsubouchi, M., Takada, H., Okamura, K., 1982, investigation into plasto-hydrodynamic lubrication with a cold sheet drawing test, CIRP AnnManuf Techn 31/1:175-180.

[3] Azushima, A., 1995, Direct observation of contact behaviour to interpret the coefficient of friction in sheet metal forming, CIRP Ann-Manuf Techn, 44/1:209212.

[4] Bech, J., Bay, N., Eriksen, M., 1999, Entrapment and escape of liquid lubricant in metal forming, Wear, 232:134-139.

[5] Deltombe, R., Belotserkovets, A., Dubar, M., Dubois, M., Dubar, L., 2011, Local approach strategy to predicting final roughness in cold rolling of stainless steel strips, P I Mech Eng J-J Eng, 225/9:887-893.

[6] C. Hubert, N. Bay, P. Christiansen, R. Deltombe, L. Dubar, M. Dubar, A. Dubois: Numerical simulation of lubrication mechanisms at mesoscopic scale. Proceed. 14th Int. ESAFORM Conf., Queen's University Belfast, 27 - 29 April 2011. AIP Conf. Proc., pp. 1729-1734, april, ISBN 978-0-7354- 0911-8.

[7] N. Bay, T. Wanheim: Contact phenomena under bulk plastic deformation conditions. Keynote paper at Symp. on Lubrication Mechanisms in Metal Forming at 3rd Int. Conf. on Technol. of Plasticity, Kyoto (1990) v. IV, p. 16771691. 